\title{
Comparison-induced decoy effects
}

\author{
JESSICA M. CHOPLIN \\ DePaul University, Chicago, Illinois \\ and \\ JOHN E. HUMMEL \\ University of California, Los Angeles, California
}

\begin{abstract}
Extant theories of decoy effects on evaluations of attribute values were assessed with respect to their ability to account for a one-dimensional analogue of the asymmetric dominance effect. Parducci's (1965, 1995) range-frequency theory, Krumhansl's (1978) distance-density model, Tversky's (1977) diagnosticity principle, and reference point theories (e.g., Holyoak \& Mah, 1982) were unable to account for this effect. One version of Helson's (1964) adaptation-level theory and our comparisoninduced distortion theory (Choplin \& Hummel, 2002) were able to account for the qualitative effect. Quantitative fits revealed that comparison-induced distortion theory provides a better account of this effect than does adaptation-level theory. These results suggest that, in some cases, biases created by language-expressible magnitude comparisons mediate the effects of decoys on evaluation.
\end{abstract}

In the asymmetric dominance effect (ADE), the introduction of a decoy item into a choice set biases the decisions people make. For example, Huber, Payne, and Puto (1982) asked their participants to choose between a fivestar restaurant that was a 25-min drive away and a threestar restaurant that was a 5-min drive away. These two choices were designed to be equally desirable by making the subjective benefit of the five-star restaurant's better food quality equal to the subjective benefit of the closer restaurant's shorter driving distance. A decoy restauranta restaurant that no one would actually choose because it was worse in every respect than one of the two original choices-was introduced into the choice set. When a four-star restaurant that was a 35-min drive away was added to the choice set as the decoy, participants tended to prefer the five-star restaurant that was a 25-min drive away. However, when a two-star restaurant that was a 15min drive away was added as the decoy, participants tended to prefer the three-star restaurant that was a 5-min drive away. That is, participants preferred the option that was consistently better than the decoy (henceforth, called the dominating option).

Decoy effects like the ADE are significant from both practical and theoretical standpoints. From a practical standpoint, decoy effects directly impact real-life decisions such as consumer product selection (e.g., Doyle, O'Connor, Reynolds, \& Bottomley, 1999), choice of

We thank Doug Wedell, Doug Medin, Keith Holyoak, Amos Tversky, Carol Krumhansl, Rob Goldstone, Tom Palmeri, Brad Love, two anonymous reviewers, and - most of all-Gordon Logan for helpful discussions, and we also thank Tammy Caplan for help running participants. Correspondence concerning this article may be addressed to J. M. Choplin, DePaul University, Department of Psychology, 2219 North Kenmore Avenue, Chicago, IL 60614-3504 (e-mail: jchoplin@depaul.edu). which candidate to support in an election (Pan, O'Curry, $\&$ Pitts, 1995), decisions about whom to hire (Highhouse, 1996), and mate selection (Sedikides, Ariely, \& Olsen, 1999). From a theoretical standpoint, decoy effects provide a powerful tool to investigate theories of attribute evaluation-theories that have wide-ranging implications not only for decision making but also for similarity, categorization, and cognition generally.

Research on the ADE has concentrated on three factors that are each capable of explaining the effect: changes in the weight given to each attribute dimension (Ariely \& Wallsten, 1995; but see Wedell \& Pettibone, 1996); changes in the evaluation of particular attribute values lying on each of the dimensions (Choplin \& Hummel, 2002; Huber et al., 1982; Wedell \& Pettibone, 1996); and the relationships between options used to justify one choice over its alternatives (Roe, Busemeyer, \& Townsend, 2001; Simonson, 1989; Wedell, 1991). Our purpose in pursuing the research reported here was to study one of the three factors - namely, changes in the evaluation of attribute values - in greater depth. In particular, we wanted to investigate theories of attribute-value evaluation with respect to their ability to account for changes in evaluation caused by the insertion of decoys into the set of items whose attribute values are being evaluated.

Decoy effects provide a powerful tool to study theories of attribute-value evaluation because the relatively simple manipulation of inserting a single decoy simultaneously changes many of the factors thought to affect attributevalue evaluation. Adding a decoy potentially changes the mean (Helson, 1964), the range (Parducci, 1965, 1995; Volkmann, 1951), and the density or frequency (Krumhansl, 1978; Parducci, 1965, 1995) of the distribution. Adding a decoy also potentially changes reference points (Frederick \& Loewenstein, 1999; Holyoak \& Mah, 1982), 
likely groupings between items (Tversky, 1977), and the relationships between items (Choplin \& Hummel, 2002). Because theories of how these factors affect attributevalue evaluation often make conflicting predictions, decoy effects allow us to pit theories of attribute-value evaluation directly against each other.

The traditional ADE paradigm has made it very difficult to study changes in attribute-value evaluation in isolation from changes in the weight given to attribute dimensions and the effects of relational information used to justify one choice over its alternatives, however, because the paradigm has always used at least two dimensions (see Figure 1; e.g., restaurant quality and driving distance in the Huber et al., 1982, experiment described above) and has required a choice among alternatives. It has, thereby, confounded each of these three factors with the others (but see Wedell \& Pettibone, 1996). To isolate the effects of decoys on attribute-value evaluation from the effects of decoys on the other two factors, we developed a one-dimensional analogue of the ADE and used similarity judgments as the dependent measure. Because this paradigm used stimuli that varied along a single dimension, the effects of decoys on the evaluation of at-
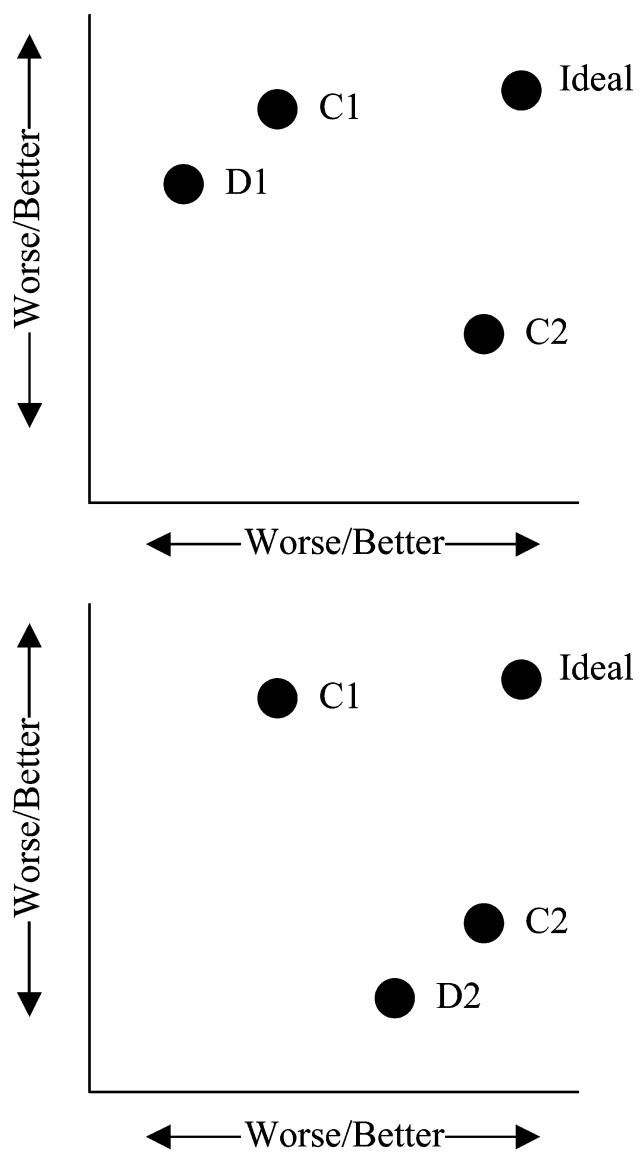

Figure 1. The asymmetric dominance effect. Medin, Goldstone, and Markman (1995) predicted that inserting a decoy would make the item that dominated it appear more similar to the ideal. tribute values were not confounded by possible changes in the weight given to attribute dimensions (Ariely \& Wallsten, 1995) or by tradeoffs between dimensions (Simonson \& Tversky, 1992; Tversky \& Simonson, 1993). Because this paradigm used similarity judgments as the dependent measure, it was able to eliminate the need to choose an option (Roe et al., 2001) and the need to justify choices (Simonson, 1989; as in Experiment 3 below). We describe four experiments that demonstrate a onedimensional analogue of the ADE wherein the effects of changes in evaluations of attribute values are not confounded by changes in the weight given to attribute dimensions. One of these experiments (Experiment 3) also eliminated the need to make and justify choices. We then assess current theories of attribute-value evaluation with respect to their ability to account for this one-dimensional analogue.

\section{A One-Dimensional Analogue of the ADE}

Designing a one-dimensional analogue of the ADE was complicated by the fact that two choices that lie along a single dimension are rarely equally desirable. Extreme values are most preferred on many dimensions. The preferred distance is a 0 -min drive away; the preferred restaurant quality is a five-star rating; and the preferred price is free. (There are, of course, exceptions - e.g., sweetness.) To make middle values most preferred, we used a technique suggested by Medin, Goldstone, and Markman (1995). They suggested that effects analogous to the ADE ought to be observable using similarity judgments as the dependent measure. For example, imagine if the participants in an experiment analogous to the Huber et al. (1982) experiment described above were asked to judge the similarity of the five-star restaurant that was a 25 -min drive away and the three-star restaurant that was a 5-min drive away to an ideal five-star restaurant that was next door. Medin et al. predicted that the insertion of decoys would likely bias judged similarity to the ideal (see Figure 1). For example, participants who observe a four-star restaurant that is a 35-min drive away as the decoy might judge the five-star restaurant that is a 25-min drive away as the most similar to the ideal restaurant. By contrast, participants who observe a two-star restaurant that is a $15-\mathrm{min}$ drive away as the decoy might judge the three-star restaurant that is a 5-min drive away as the most similar to the ideal. We adopted Medin et al.'s suggestion and used a similarity judgment paradigm to create a one-dimensional analogue of the ADE.

In particular, the experiments we report in this article presented participants with items that varied along a single, nonhedonic dimension (i.e., aspect ratio in Experiment 1 or line length in Experiments 2 through 4; see Figure 2). These items included a target item (T) and two choice items. One of the choice items was smaller than $\mathrm{T}(\mathrm{C}-)$, and the other was larger than $\mathrm{T}(\mathrm{C}+)$. The distance between $\mathrm{C}-$ and $\mathrm{T}$ was approximately the same as the distance between $\mathrm{C}+$ and $\mathrm{T}$. A decoy that was either smaller than $\mathrm{C}-$ or larger than $\mathrm{C}+$ was also included. The participants' task was to judge the similarity of $\mathrm{C}-$ 

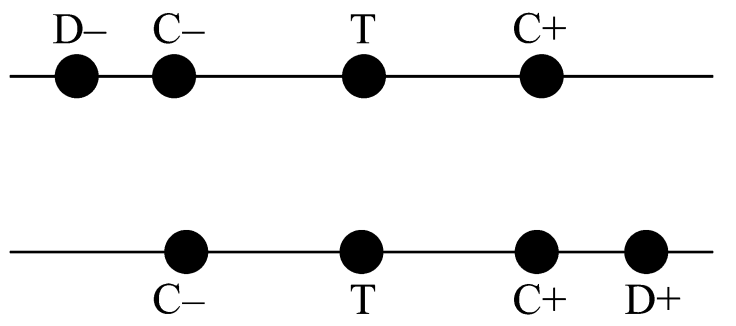

\section{Dimension}

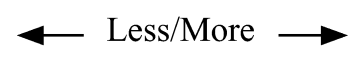

\begin{abstract}
Figure 2. The unidimensional analogue of the asymmetric dominance effect. The task was to judge which item was most similar to $T$.
\end{abstract}

and $\mathrm{C}+$ to the target item, $\mathrm{T}$. If the effects of decoys on attribute-value evaluations in these experiments are analogous to the effects of decoys on attribute-value evaluations in the $\mathrm{ADE}$, then participants who view decoys that are slightly smaller than $\mathrm{C}-(\mathrm{D}-)$ will judge $\mathrm{C}-$ more similar to $\mathrm{T}$ than they judge $\mathrm{C}+$ to $\mathrm{T}$. Participants who view decoys that are slightly larger than $\mathrm{C}+(\mathrm{D}+)$ will judge $\mathrm{C}+$ to be more similar to $\mathrm{T}$ than they judge $\mathrm{C}-$ to $\mathrm{T}$.

We used artificial stimuli (ovals that varied in aspect ratio and line segments that varied in length) in these experiments to avoid problems associated with dimensions on which people have hedonic preferences. Although it may have been possible to test theories of attribute-value evaluation using dimensions on which people prefer middle values (e.g., sweetness), such experiments would likely have been problematic for several reasons. For a start, people are likely to associate extraneous attributes with these dimensions. For example, people might associate increased sweetness with increased calories or carcinogenic properties. The experiment would then, in effect, become a two-dimensional experiment. By using artificial stimuli, we could be reasonably certain that the stimuli only varied on a single dimension. Furthermore, loss aversion explanations might provide a tenable explanation for effects involving a dimension on which people have hedonic preferences (especially if the task were inadvertently to become two-dimensional; see Tversky \& Kahneman, 1991), because the middle option might represent less of a loss in its similarity to the ideal than the other two options. By contrast, using artificial stimuli and similarity judgments as the dependent measure makes loss-aversion explanations of one-dimensional decoy effects untenable, because no loss is involved in judging the relative similarities of ovals or line segments to each other.

We performed four experiments investigating the effects of decoys on evaluations of attribute values. The decoys in Experiments 1-3 were either slightly smaller than $\mathrm{C}-(\mathrm{D}-)$ or slightly larger than $\mathrm{C}+(\mathrm{D}+)$. Experiments 1 and 2 investigated the effects of these decoys using a forced choice paradigm in which the participants identified the item (i.e., $\mathrm{C}-, \mathrm{C}+$, or the decoy) that they thought was most similar to the target. To avoid effects of decision heuristics (Roe et al., 2001; Simonson,
1989), Experiment 3 used a similarity rating paradigm in which the participants rated the similarity of $\mathrm{C}-$ and $\mathrm{C}+$ to the target. Experiment 4 was modeled after Experiment 2 and investigated the effects of decoys that extend the range of attribute values beyond the extensions introduced by the decoys in Experiment 2. Extant theories of attribute-value evaluation were then assessed with respect to their ability to account for the results of these experiments.

\section{EXPERIMENT 1}

Experiment 1 investigated whether decoy effects analogous to the decoy effects observed in the ADE could be observed using stimuli that varied on a single dimension. Extensive research on integral versus separable dimensions has found that aspect ratio is processed as a single dimension (e.g., Garner, 1974). On the basis of this research, Experiment 1 used ovals that varied in aspect ratio (where aspect ration is defined as height divided by width; see Figure 3).

\section{Method}

Participants. The participants were 202 undergraduates from the University of California, Los Angeles, who participated as part of a class demonstration. Participation was voluntary. Two participants' data were removed from analysis, because they refused to specify a single answer in our forced choice question, leaving 200 responses for analysis - 101 participants viewed the $\mathrm{D}-$ decoy, and 99 participants viewed the D+ decoy (see Figure 2).

Materials and Procedure. The ovals were presented on $8.5 \times$ 5.5 in. pieces of paper. The target oval, T, had an aspect ratio of $1.64, \mathrm{C}+$ had an aspect ratio of 1.95 , and $\mathrm{C}-$ had an aspect ratio of 1.33. We kept the objective differences between $\mathrm{C}-$ and $\mathrm{T}$ in height and width the same as the objective differences between $\mathrm{C}+$ and $\mathrm{T}$. Although we did no formal testing prior to the experiment to verify that the subjective differences were identical, the results of the experiment (presented shortly) make it clear that the subjective differences were within the necessary range to produce differences in ordinal similarities. The decoys, $\mathrm{D}-$ and $\mathrm{D}+$, had aspect ratios of 1.07 and 2.29, respectively. As shown in Figure 3, we manipulated which decoy oval $(\mathrm{D}+$ or $\mathrm{D}-$ ) was presented. The target was presented on top, and the three choice ovals were presented on the bottom (as in Figure 3). The leftmost choice oval was labeled $A$, the middle oval $B$, and the rightmost $C$. Immediately below the choice ovals, the participants were asked to pick which figure $(A, B$, or $C)$ looked most similar to the top figure, and they were given a space in which to write their response. There were four experimental handouts, two in each experimental condition. The decoy (D+ or $\mathrm{D}-$ ) was always presented in the middle and labeled $B$. To control for order effects in left-to-right presentation, the assignment of $\mathrm{C}+$ and $\mathrm{C}$ - to $A$ (left) or $C$ (right) was counterbalanced. One of the four experimental handouts was randomly assigned to each participant. The participants read the question, answered it, and returned the handout to the experimenter.

\section{Results}

The results are shown in Figure 3. As in the ADE, the decoy increased the likelihood that participants would choose the item that was similar to it (i.e., the decoysided choice item). In the $\mathrm{D}-$ condition, $59.8 \%$ of the participants (61 responses) picked $\mathrm{C}-$, the decoy-sided choice item, as the most similar to the target, and only 
D+ Condition

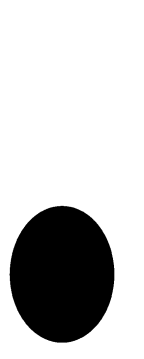

$(\mathrm{C}-)$

$42 \%$

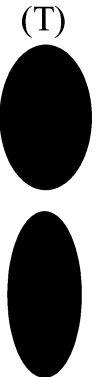

(D+)

$1 \%$

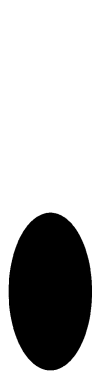

$(\mathrm{C}+)$

$57 \%$
D- Condition
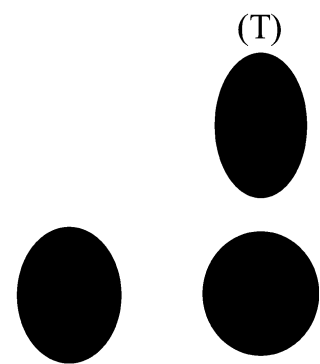

(D-)

$(\mathrm{C}-)$

$59.8 \% \quad 1 \%$

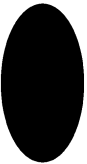

$(\mathrm{C}+)$

$39.2 \%$

Figure 3. Stimuli and results from Experiment 1. The participants who viewed the $\mathrm{D}+$ decoy oval picked $\mathrm{C}+$ as most similar to the target $57 \%$ of the time and $\mathrm{C}-\mathbf{4 2 \%}$ of the time. The participants who viewed $D-$ picked $C-$ as most similar to the target $59.8 \%$ of the time and $\mathrm{C}+\mathbf{3 9 . 2} \%$ of the time.

$39.2 \%$ (40 responses) picked $\mathrm{C}+$, the decoy-opposite choice item. One participant, $1 \%$, picked the decoy. In the $\mathrm{D}+$ condition, $57 \%$ of the participants (57 responses) picked $\mathrm{C}+$, the decoy-sided choice item, as the most similar to the target, and only $42 \%$ (42 responses) picked $\mathrm{C}-$, the decoy-opposite choice item. One participant, $1 \%$, picked the decoy. An omnibus $\chi^{2}$ analysis revealed that this interaction was significant $\left[\chi^{2}(2, N=202)=6.49\right.$, $p<.05]$, as did a $\chi^{2}$ analysis that excluded the decoy responses $\left[\chi^{2}(1, N=200)=6.47, p<.05\right]$. Further $\chi^{2}$ analyses excluding decoy responses revealed that the proportion of participants in the $\mathrm{D}-$ condition who picked $\mathrm{C}-$, the decoy-sided choice item, $(60.4 \%$ of the responses, excluding decoy responses) was significantly greater than $50 \%\left[\chi^{2}(1, N=101)=4.37, p<.05\right]$ and that the proportion of participants in the $\mathrm{D}+$ condition who picked $\mathrm{C}+$, the decoy-sided choice item, $(57.6 \%)$ did not significantly differ from $50 \%\left[\chi^{2}(1, N=99)=\right.$ $2.27, p>.05]$.

\section{EXPERIMENT 2}

Experiment 2 conceptually replicated Experiment 1 using line segments that varied in length.

\section{Method}

Participants. The participants were 146 people standing in line at a Los Angeles movie theater. Of these, 72 were in the D+ condition and 74 were in the $\mathrm{D}-$ condition. Participation was voluntary. All participants completed the task successfully.

Materials and Procedure. Unlike other dimensions, subjective differences in the lengths of line segments tend to increase at approximately the same rate as objective differences (Stevens, 1962). This idiosyncrasy of line lengths allowed us to keep the subjective difference between $\mathrm{C}-$ and $\mathrm{T}$ approximately the same as the subjective difference between $\mathrm{C}+$ and $\mathrm{T}$ by simply keeping the objective differences the same. The target line was $22 \mathrm{~mm}$ long. $\mathrm{C}+$ was $8 \mathrm{~mm}$ longer than the target (i.e., $30 \mathrm{~mm}$ ), and $\mathrm{C}-$ was $8 \mathrm{~mm}$ shorter than the target (i.e., $14 \mathrm{~mm}$ ). We did no formal testing prior to the experiment to verify that the subjective differences were identical. $\mathrm{D}+$ was $4 \mathrm{~mm}$ longer than $\mathrm{C}+$ (i.e., $34 \mathrm{~mm}$ ), and $\mathrm{D}-$ was $4 \mathrm{~mm}$ shorter than $\mathrm{C}-$ (i.e., $10 \mathrm{~mm}$ ). In every other respect, the handout was identical to that used in Experiment 1 (see Figure 4). The same procedure was also followed.

\section{Results}

The results are shown in Figure 4 and Table $1(\mathrm{D}-$ and $\mathrm{D}+$ conditions). As in the ADE, the decoy increased the likelihood that participants would choose the item that was similar to it (i.e., the decoy-sided choice item). In the $\mathrm{D}-$ condition, $62.2 \%$ of the participants (46 responses) picked $\mathrm{C}-$, the decoy-sided choice item, as the most similar to the target, while only $33.8 \%$ (25 responses) picked $\mathrm{C}+$, the decoy-opposite choice item; $4 \%$, or 3 responses, picked $\mathrm{D}-$. In the $\mathrm{D}+$ condition, $61.1 \%$ of the participants ( 44 responses) picked $\mathrm{C}+$, the decoy-sided choice item, as the most similar to the target, while only $26.4 \%$ (19 responses) picked $\mathrm{C}-$, the decoy-opposite choice item; $12.5 \%, 9$ responses, chose $\mathrm{D}+$. An omnibus $\chi^{2}$ analysis revealed that this interaction was significant $\left[\chi^{2}(2, N=146)=19.4, p<.01\right]$, as did a $\chi^{2}$ analysis that excluded the decoy responses $\left[\chi^{2}(1, N=134)=16.03, p<.01\right]$. Further $\chi^{2}$ analyses excluding the decoy responses revealed that the proportion of participants in the $\mathrm{D}-$ condition who picked the $\mathrm{C}-$, the decoy-sided choice item $(64.8 \%$ of the responses), was significantly greater than $50 \%\left[\chi^{2}(1, N=\right.$ $63)=9.92, p<.01]$ and that the proportion of participants in the $\mathrm{D}+$ condition who picked the $\mathrm{C}+$ item, the decoy-sided choice item $(69.8 \%)$, was also significantly greater than $50 \%\left[\chi^{2}(1, N=71)=6.21, p<.05\right]$.

\section{Discussion, Experiments 1 and 2}

The results demonstrated a one-dimensional decoy effect analogous to the ADE. The participants who viewed 


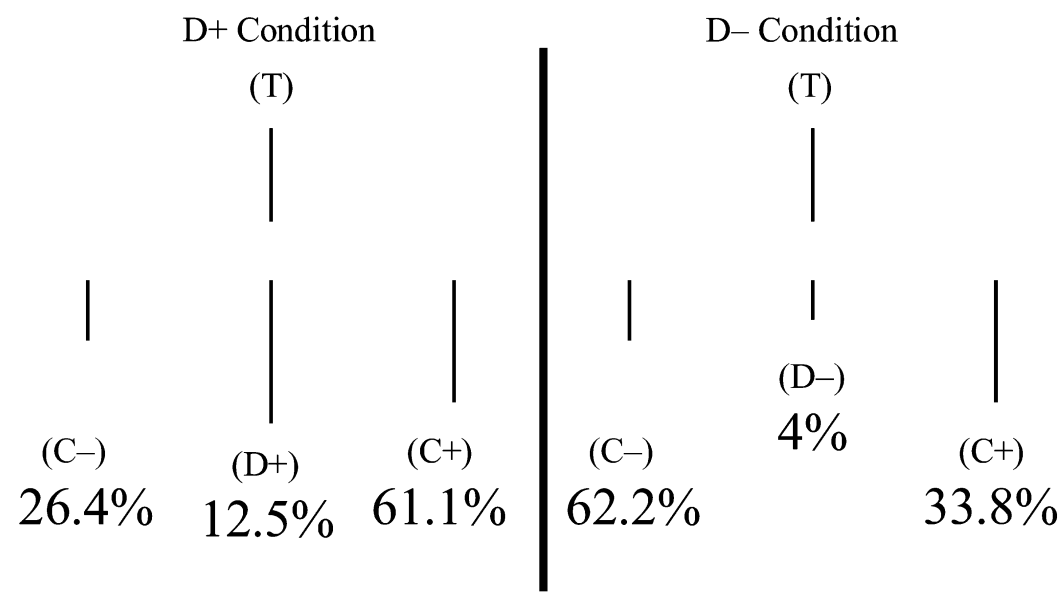

Figure 4. Stimuli and results from Experiment 2. The participants who viewed the $D+$ decoy picked $C+$ as most similar to the target $61.1 \%$ of the time and $C-26.4 \%$ of the time. The participants who viewed $\mathrm{D}-$ picked $\mathrm{C}-$ as most similar to the target $62.2 \%$ of the time and $\mathrm{C}+\mathbf{3 3 . 8 \%}$ of the time.

the $\mathrm{D}-$ decoy tended to choose $\mathrm{C}-$ as most similar to the target, whereas participants who viewed the $\mathrm{D}+$ decoy tended to choose $\mathrm{C}+$ as most similar to the target. Because these stimuli varied along a single dimension (aspect ratio in Experiment 1 and length in Experiment 2), changes in the weight given to dimensions cannot explain these results.

\section{EXPERIMENT 3}

One potential criticism of Experiments 1 and 2 is that the forced choice paradigm might have placed constraining demands on our participants' judgments of similarity. Given the need to choose, factors other than changes in evaluations of attribute values (i.e., decision heuristics)

Table 1

Observed Response Frequencies in Experiments 2 and 4 (Excluding Decoy Responses) and the Best-Fitting Response Frequency Predictions of Adaptation Level (AL) Theory and Comparison-Induced Distortion (CID) Theory

\begin{tabular}{|c|c|c|c|c|c|}
\hline & $N$ & Response & $\begin{array}{l}\text { Observed } \\
\text { Frequency }\end{array}$ & $\begin{array}{c}\text { AL } \\
\text { Theory }\end{array}$ & $\begin{array}{l}\text { CID } \\
\text { Theory }\end{array}$ \\
\hline $\begin{array}{l}\text { Number of free } \\
\text { parameters }\end{array}$ & & & & 1 & 2 \\
\hline $\begin{array}{l}\text { Best-fitting value } \\
\text { for parameter } c\end{array}$ & & & & 0.03 & 28.82 \\
\hline $\begin{array}{l}\text { Best-fitting value } \\
\quad \text { for parameter } w\end{array}$ & & & & & .001 \\
\hline $\mathrm{D}---$ & 75 & $\begin{array}{l}\mathrm{C}- \\
\mathrm{C}+\end{array}$ & $\begin{array}{l}54 \\
21\end{array}$ & $\begin{array}{l}44.13 \\
30.87\end{array}$ & $\begin{array}{l}48.85 \\
26.15\end{array}$ \\
\hline $\mathrm{D}--$ & 76 & $\begin{array}{l}\mathrm{C}- \\
\mathrm{C}+\end{array}$ & $\begin{array}{l}53 \\
23\end{array}$ & $\begin{array}{l}44.06 \\
31.94\end{array}$ & $\begin{array}{l}50.83 \\
25.17\end{array}$ \\
\hline D- & 71 & $\begin{array}{l}\mathrm{C}- \\
\mathrm{C}+\end{array}$ & $\begin{array}{l}46 \\
25\end{array}$ & $\begin{array}{l}39.29 \\
31.71\end{array}$ & $\begin{array}{l}51.06 \\
19.94\end{array}$ \\
\hline $\mathrm{D}+$ & 63 & $\begin{array}{l}\mathrm{C}- \\
\mathrm{C}+\end{array}$ & $\begin{array}{l}19 \\
44\end{array}$ & $\begin{array}{l}28.13 \\
34.87\end{array}$ & $\begin{array}{l}29.72 \\
33.28\end{array}$ \\
\hline $\mathrm{D}++$ & 76 & $\begin{array}{l}\mathrm{C}- \\
\mathrm{C}+\end{array}$ & $\begin{array}{l}37 \\
39\end{array}$ & $\begin{array}{l}29.97 \\
46.03\end{array}$ & $\begin{array}{l}43.26 \\
32.74\end{array}$ \\
\hline $\mathrm{D}+++$ & 74 & $\begin{array}{l}\mathrm{C}- \\
\mathrm{C}+\end{array}$ & $\begin{array}{l}45 \\
29\end{array}$ & $\begin{array}{l}29.18 \\
44.82\end{array}$ & $\begin{array}{l}43.80 \\
30.20\end{array}$ \\
\hline $\begin{array}{l}\text { Minimized negative } \\
\text { log-likelihood* }\end{array}$ & & & & 13.55 & 8.92 \\
\hline $\begin{array}{l}\text { Bayesian information } \\
\text { criterion* }^{*}\end{array}$ & & & & 27.88 & 19.40 \\
\hline
\end{tabular}

*Smaller values indicate a better fit. 
could produce ADE-like patterns of decoy effects on similarity judgments. Simonson (1989) suggested that participants faced with a choice about which they are indifferent might search for a justification for choosing one option over the other. The fact that $\mathrm{C}$ - was obviously more similar to $\mathrm{T}$ than was $\mathrm{D}-$ in the $\mathrm{D}-$ condition and that $\mathrm{C}+$ was obviously more similar to $\mathrm{T}$ than was $\mathrm{D}+$ in the $\mathrm{D}+$ condition could have presented them with a justification for choosing the decoy-sided choice item. (Note, however, that this justification involves magnitude comparisons and could, thereby, create changes in evaluations of attribute values; see Choplin \& Hummel, 2002.) Similarly, Roe et al.'s (2001) connectionist account of choice assumes that decisions are aided by lateral inhibition between nodes that represent options. Roe et al.'s model might account for these effects if the decoy-being inferior to both of the other options - fell into a negative preference state and the lateral inhibition between the decoy and the decoy-sided choice item became excitation (because the negative from the preference state would cancel out the negative from the lateral inhibition). The excitation could have then biased our participants' preferences toward the decoy-sided choice item. These theories are not applicable to tasks in which no choice is involved.

To investigate whether one-dimensional ADE-like decoy effects are observable using a paradigm in which no choice is involved, Experiment 3 used a similarity rating paradigm. Participants rated the similarity of both the $\mathrm{C}+$ and $\mathrm{C}-$ items to the target. This change in the dependent measure allowed participants to say that $\mathrm{C}+$ and $\mathrm{C}$ - were equally similar to the target and eliminated the need to choose one option over another. There was, therefore, no need to justify one choice over its alternatives (Simonson, 1989; Wedell, 1991) or for lateral inhibition between options (Roe et al., 2001). Decision heuristics such as those discussed by Simonson and Roe et al. are not applicable to this task.

\section{Method}

Participants. The participants were 130 people (64 in the D+ condition, 66 in the $\mathrm{D}-$ condition) standing in line at a Los Angeles movie theater. Participation was voluntary. All completed the task successfully.

Materials and Procedure. T was $39 \mathrm{~mm}$ long. C+ was $7 \mathrm{~mm}$ longer than $\mathrm{T}$ (i.e., $46 \mathrm{~mm}$ ), and $\mathrm{C}-$ was $7 \mathrm{~mm}$ shorter (i.e., $32 \mathrm{~mm}$ ). $\mathrm{D}+$ was $2 \mathrm{~mm}$ longer than $\mathrm{C}+$ (i.e., $48 \mathrm{~mm}$ ), and $\mathrm{D}-$ was $2 \mathrm{~mm}$ shorter than C- (i.e., $30 \mathrm{~mm}$ ). As in Experiments 1 and 2, we manipulated which decoy $(\mathrm{D}+$ or $\mathrm{D}-$ ) was presented. The four lines were presented at the top of a handout, arrayed in a single row and labeled $A$ through $D$ from left to right. In order to conserve space on the page, the four lines were presented at a $45^{\circ}$ angle. Three random orders were created: (1) choice item, decoy, choice item, target; (2) target, decoy, choice item, choice item; (3) choice item, target, decoy, choice item. Within each order, the locations of the choice items $(\mathrm{C}-$ and $\mathrm{C}+)$ were counterbalanced, creating a total of six orders per condition (i.e., a total of 12 experimental handouts in the experiment as a whole). The labels $A$ through $D$ associated with these lines depended on their left-to-right positions. Below these lines, participants rated the similarity of both $\mathrm{C}+$ and $\mathrm{C}-$ to $\mathrm{T}$ on a scale from 0 (not similar) to 10 (very similar). The participants received one of the 12 handouts, performed the tasks, and returned the handout to the experimenter.

\section{Results}

The similarity rating results were analyzed using a 2 (decoy item: $\mathrm{D}-$ or $\mathrm{D}+) \times 2$ (choice item: $\mathrm{C}-$ and $\mathrm{C}+$ ) mixed-factors analysis of variance (ANOVA). This analysis found that the decoys produced an ADE-like effect, as revealed by an interaction wherein the ratings of the two choice items depended upon which decoy item was presented $\left[F(1,128)=5.75, M S_{\mathrm{e}}=6.54, p<.05\right]$. A post hoc least significant difference analysis revealed that the participants who saw the $\mathrm{D}+$ decoy rated the similarity of $\mathrm{C}+$ (i.e., the decoy-sided choice item) to the target $(M=6.06, S D=2.98)$ significantly higher than they rated the similarity of $\mathrm{C}-$ (i.e., the decoyopposite choice item) to the target $(M=4.86, S D=$ 3.01). The difference in how similar the participants who saw the $\mathrm{D}-$ decoy rated $\mathrm{C}-(M=5.61, S D=3.24)$ and $\mathrm{C}+(M=5.29, S D=3.18)$ to the target failed to reach significance. The ANOVA did not find main effects of the decoy item that was presented [D-, $M=5.45, S D=$ $3.20 ; \mathrm{D}+, M=5.46, S D=3.05 ; F<1]$ or of the choice item that participants rated $[\mathrm{C}-, M=5.23, S D=3.14$; $\mathrm{C}+, M=5.68, S D=3.10 ; F(1,128)=1.94, M S_{\mathrm{e}}=$ $6.54, p>.05]$.

\section{Discussion}

The results again demonstrated a one-dimensional decoy effect analogous to the ADE. Because the participants never made a choice, decision heuristics are not applicable to this task. Simonson's (1989) choice justification theory is not applicable to this task because the participants made no choices. Roe et al.'s (2001) suggestion that lateral inhibition-used to winnow one's options - might create decoy effects is also not applicable to this task, because there was no need to winnow options in this similarity-rating paradigm. These results also demonstrate that one-dimensional ADE-like decoy effects are observable using a different physical layout from that used in Experiments 1 and 2.

\section{EXPERIMENT 4}

In Experiments 1-3, analogy to the ADE suggested that inserting the $\mathrm{D}-$ decoy would make $\mathrm{C}-$ appear more similar to the target than $\mathrm{C}+$ and inserting the $\mathrm{D}+$ decoy would make $\mathrm{C}+$ appear more similar to the target than $\mathrm{C}-$. In Experiment 4, we investigated the effects of decoys that extend the range beyond the extensions introduced by the $\mathrm{D}-$ and $\mathrm{D}+$ decoys. Decoys that were smaller than $\mathrm{D}-$ (i.e., smaller, $\mathrm{D}--$, or much smaller, $\mathrm{D}---$ ) or larger than $\mathrm{D}+$ (i.e., larger, $\mathrm{D}++$, or much larger, $\mathrm{D}+++$ ) were introduced into the set of items whose attribute values were evaluated. Analogy to the $\mathrm{ADE}$ suggests that further extensions of the range may 
not matter. Huber et al. (1982) and Huber and Puto (1983), for example, manipulated the distance between the decoy and the item that dominated it. They found that extending the range by moving the decoy farther away did not increase the size of the ADE. Likewise, extending the range may not increase the size of this onedimensional ADE analogue.

\begin{abstract}
Method
Participants. The participants were 316 people at a Los Angeles cultural festival. Participation was voluntary. Of the 316 participants, 8 failed to follow instructions, and their responses were not analyzed. Of the 308 participants whose responses were analyzed, 77 were in each of the $\mathrm{D}---, \mathrm{D}--, \mathrm{D}++$, and $\mathrm{D}+++$ conditions, respectively.

Materials and Procedure. The materials and procedure were identical to those used in Experiment 2, except that a pretest was used to determine the lengths of the decoy line segments (this pretest will be discussed in greater depth in our discussion of comparisoninduced distortion theory below). The participants in one group imagined and drew a line that was shorter than a presented $14-\mathrm{mm}$ line (i.e., the length of $\mathrm{C}-$ ). The 10th and 20th percentiles of drawn lines were used as the lengths of the $\mathrm{D}---(2-\mathrm{mm})$ and $\mathrm{D}--(4-$ $\mathrm{mm}$ ) decoy lines, respectively. The participants in a separate group imagined and drew a line that was longer than a presented $30-\mathrm{mm}$ line (i.e., the length of $\mathrm{C}+$ ). The 80 th and 90 th percentiles of drawn lines were used as the lengths of the $\mathrm{D}++(79-\mathrm{mm})$ and $\mathrm{D}+++$ (95-mm) decoy lines, respectively. We manipulated which decoy (D-- - , D- - , D + +, or D +++ ) was presented. To make room to present the $\mathrm{D}++$ and $\mathrm{D}+++$ decoys, the target line was placed at the upper left hand corner of the page. The participants received a randomly selected experimental handout, identified the line they thought was most similar to the target by circling it, and returned the handout to the experimenter.
\end{abstract}

\section{Results}

The results are shown in Table $1(\mathrm{D}---, \mathrm{D}--, \mathrm{D}++$, and $\mathrm{D}+++$ conditions). The extensions in the range created by these decoys beyond the extensions created by the decoys in Experiment 2 seem to have reduced the ADE-like effect found in Experiment 2. In all conditions except the $\mathrm{D}++$ condition, participants were biased to choose the $\mathrm{C}-$ item as most similar to $\mathrm{T}$. In the $\mathrm{D}++$ condition, approximately half of the participants chose $\mathrm{C}-$ and half chose $\mathrm{C}+$ as most similar to $\mathrm{T}$. In addition to the results presented in Table 1,2 participants in the $\mathrm{D}---$ condition, 1 in the $\mathrm{D}--$ condition, 1 in the $\mathrm{D}++$ condition, and 3 in the $\mathrm{D}+++$ condition picked the decoy. An omnibus $\chi^{2}$ analysis revealed that the pattern of results varied across conditions $\left[\chi^{2}(6, N=308)=\right.$ $12.57, p=.05]$, as did a $\chi^{2}$ analysis that excluded the decoy responses $\left[\chi^{2}(3, N=301)=10.88, p<.05\right]$. Further $\chi^{2}$ analyses excluding the decoy responses revealed that the proportion of participants in the $\mathrm{D}---$ condition who picked the $\mathrm{C}-$ item $(72 \%$ of the $\mathrm{C}$-item responses) was significantly greater than $50 \%\left[\chi^{2}(1, N=\right.$ $75)=14.52, p<.01]$. The proportion of participants in the $\mathrm{D}--$ condition who picked the $\mathrm{C}-$ item $(69.7 \%$ of the $\mathrm{C}$-item responses) was also significantly greater than $50 \%\left[\chi^{2}(1, N=76)=11.84, p<.01\right]$. The proportion of participants in the $\mathrm{D}++$ condition who picked the $\mathrm{C}-$ item $(48.7 \%$ of the $\mathrm{C}$-item responses) was not significantly different from $50 \%\left[\chi^{2}(1, N=76)=0.05, p>\right.$ $.05]$. The proportion of participants in the $\mathrm{D}+++$ condition who picked the $\mathrm{C}-$ item $(60.8 \%$ of the $\mathrm{C}$-item responses) was marginally greater than $50\left[\chi^{2}(1, N=77)=\right.$ $3.46, p<.1]$.

\section{MODELS OF ATTRIBUTE-VALUE EVALUATION}

In four experiments, we found that decoys produce ADE-like effects on evaluations of attribute values that lie on a single dimension. Not all theories of attributevalue evaluation can account for this effect. We assessed a sample of well-known theories of attribute-value evaluation with respect to their ability to account for this finding.

\section{Range-Frequency Theory}

Parducci's $(1965,1995)$ range-frequency theory is often cited as a potential explanation for the ADE (e.g., Huber et al., 1982; Wedell \& Pettibone, 1996). Although this theory can account for the effects of decoys on the evaluations of attribute values in the two-dimensional ADE task shown in Figure 1, it cannot account for the decoy effects observed in the one-dimensional analogue. According to range-frequency theory, judgments are affected by two factors: the position of an item's value within the range of contextual values and an item's percentile rank. Neither of these factors would alter the ordinal similarities in this one-dimensional analogue. The extension of the range created by introducing a decoy item would reduce both the percentage of the range between $\mathrm{C}-$ and $\mathrm{T}$ and the percentage of the range between $\mathrm{C}+$ and $\mathrm{T}$, and this reduction would be approximately the same for both items. Therefore, the range principle cannot account for the observed decoy effects. The change in rank created by introducing the decoy item also would not have altered ordinal similarities, because the relevant rank positions remained adjacent. When $\mathrm{D}---, \mathrm{D}--$, or $\mathrm{D}-$ was inserted into the context, $\mathrm{C}$ - was the second value, $\mathrm{T}$ was the third, and $\mathrm{C}+$ was the fourth. The difference in rank between $\mathrm{C}-$ and $\mathrm{T}$ was one place, as was the difference in rank between $\mathrm{C}+$ and $\mathrm{T}$. Likewise, when $\mathrm{D}+$, $\mathrm{D}++$, or $\mathrm{D}+++$ was inserted into the context, $\mathrm{C}-$ was the first value, $\mathrm{T}$ was the second, and $\mathrm{C}+$ was the third. Again, the difference in rank between $\mathrm{C}$ - and $\mathrm{T}$ was one place, as was the difference in rank between $\mathrm{C}+$ and $\mathrm{T}$. Therefore, the frequency principle also cannot account for the observed one-dimensional ADE-like decoy effects.

\section{Krumhansl's Distance-Density Model}

According to Krumhansl's (1978) distance-density model of similarity, people are more sensitive to differences - are able to make finer distinctions - in more densely populated regions of similarity space. Because 
the decoys increased the density of the region surrounding their respective values, they ought to have affected the similarity of $\mathrm{C}-$ and $\mathrm{C}+$ to $\mathrm{T}$. However, the decoy effect that would have been predicted by the distancedensity model is the opposite of the observed effect: In our experiments, $\mathrm{D}+$ increased the density around $\mathrm{C}+$. It, therefore, should have increased sensitivity in that region of similarity space and made items in that region (i.e., $\mathrm{C}+$ and $\mathrm{T}$ ) seem less similar to each other. Thus, contrary to the observed results, $\mathrm{C}-$ should have seemed more similar to $\mathrm{T}$ than did $\mathrm{C}+$ in the $\mathrm{D}+$ condition. Analogously, D- increased the density around C-. It, therefore, should have increased sensitivity in that region of similarity space and made items in that region (i.e., $\mathrm{C}-$ and $\mathrm{T}$ ) seem less similar to each other. Thus, contrary to the observed results, in the $\mathrm{D}-$ condition, $\mathrm{C}+$ should have seemed more similar to $\mathrm{T}$ than $\operatorname{did} \mathrm{C}-$ in the D- condition.

\section{Tversky's Diagnosticity Principle}

According to Tversky's (1977) diagnosticity principle, items that are grouped together ought to be judged more similar. This theory holds that when $\mathrm{D}+$ was presented, it should have been grouped with $\mathrm{C}+$, leaving $\mathrm{C}-$ to be grouped with the target. $\mathrm{C}-$ would then have been judged the most similar to the target. Analogously, when $\mathrm{D}$ - was presented, it should have been grouped with $\mathrm{C}-$, leaving $\mathrm{C}+$ to be grouped with the target. $\mathrm{C}+$ would then have been judged the most similar to the target. Therefore, Tversky's diagnosticity principle would have predicted a pattern opposite the observed ADE-like effect (see also Medin et al., 1995).

\section{Reference Point Theories}

Reference point theories assume that attribute values are evaluated with respect to a reference point. Typically, similarity space is thought to be warped around the reference point in such a way in such a way that people are more sensitive to differences in that area rather than in other areas of similarity space (Frederick \& Loewenstein, 1999; Holyoak \& Mah, 1982; see Helson's, 1964, adaptation-level theory, discussed shortly, for an exception). In Experiments 1-4, the plausible reference points were the target's value, the average, and the decoy's value. If the target's value were the reference point, there would have been no difference between the $\mathrm{D}+$ and $\mathrm{D}-$ decoy conditions, because the reference point would have remained unchanged across conditions. If either the average or the decoy's value were the reference point, a pattern opposite to the observed ADE-like effects would have been expected. Sensitivity ought to have increased near the average or the decoy's value and thereby decreased the similarity between items in that region of similarity space. In that case, $\mathrm{C}$ - would have been judged less similar to $\mathrm{T}$ given $\mathrm{D}$ - rather than $\mathrm{D}+$, because the shift in the reference point toward $\mathrm{C}$ - would have made people more sensitive to differences in that region. Analogously,
$\mathrm{C}+$ would have been judged less similar to $\mathrm{T}$ in the $\mathrm{D}+$ decoy condition than in the D- decoy condition. Reference point theories, therefore, cannot account for the observed ADE-like decoy effects.

\section{Helson's Adaptation-Level Theory}

Helson's (1964) adaptation-level theory is a type of reference point theory. In adaptation-level theory, the reference point is the point participants consider to be normal (i.e., average) within a context. Stimuli are judged to have high or low values depending on their position relative to the average. Unlike other reference point theories, however, this theory does not assume that people are more sensitive to differences around the average than they are to differences in other areas of similarity space. Rather, when stimuli have values that are higher than the average, their values are simply judged to be high. When stimuli have values that are lower than the average, their values are simply judged to be low. Formally, the judgment of stimulus $i$ in context $k\left(J_{i k}\right)$ is thought to be a linear function of the difference between the context-independent value of $i$ (i.e., the actual or perceived stimulus value, $S_{i}$ ) and the adaptation level within context $k\left(\mathrm{AL}_{k}\right)$ :

$$
J_{i k}=S_{i}-\mathrm{AL}_{k}
$$

where $\mathrm{AL}_{k}$ is the average of the context-independent values (i.e., the average of actual or perceived stimulus values) in the context ( $k$ ) of which item $i$ is a member (see Wedell, 1995). This theory predicts that changes in the average of the context created by decoys ought to affect the judgment of individual items (i.e., whether items are judged to have high or low values). However, if all of the items (i.e., $\{\mathrm{C}-, \mathrm{T}, \mathrm{C}+$, decoy $\}$ ) were members of the same context, this theory would not be able to account for the observed ADE-like decoy effects on attributevalue evaluations, because changes in the average of the distribution would shift the entire judgment scale.

Nevertheless, if the target were considered to have its own context, then Helson's (1964) adaptation-level theory might account for the observed effects (see Wedell, 1995). In particular, the decoy might have affected the adaptation level - the average - within the context of the choice set (i.e., $\{\mathrm{C}-, \mathrm{C}+$, decoy $\}$ ) without affecting the adaptation level within the context of the target - wherein the target's value would be the average as it was the only item. Note that $\mathrm{C}-$ and $\mathrm{C}+$ were lower and higher, respectively, than the average in the context of the choice set. However, when D- was the decoy, C- was closer to the average, and when $\mathrm{D}+$ was the decoy, $\mathrm{C}+$ was closer to the average. If similarity judgments were made with respect to each stimulus value's proximity to the average value within its respective context, then when a $\mathrm{D}$ - was the decoy, $\mathrm{C}-$ and $\mathrm{T}$ would have been similar with respect to their proximity to the average value within their respective contexts. With a D+ decoy, $\mathrm{C}+$ and $\mathrm{T}$ would be similar with respect to the average within their respective contexts. Therefore, Helson's adaptation-level theory could 
account for the observed one-dimensional ADE-like decoy effects given the assumption that $\mathrm{T}$ is placed in a separate context from the choice set.

This version of Helson's (1964) adaptation-level theory can account for the results of Experiments 1,2, and 4, because the target in those experiments was presented above the choice set and thereby explicitly put in a separate context from the other items. This version of adaptation-level theory has more difficulty accounting for the results of Experiment 3, however. The stimuli in Experiment 3 were presented all together and in a randomized order, and thus appeared within a single context; if placement were the only relevant factor, adaptation-level theory could not account for the observed result. In defense of this adaptationlevel theory account of the observed results, one might point out that the target was the item to which the $\mathrm{C}-$ and $\mathrm{C}+$ items were compared, and therefore it may still have been placed within its own context separate from the other stimuli. If so, this version of adaptation-level theory could also account for the results of Experiment 3. This ambiguity in what does or does not constitute a context is potentially problematic for adaptation-level theory (as well as for other theories of attribute-value evaluation; see Parducci, 1995). This second version of adaptationlevel theory is nevertheless a viable model of the observed results. To examine how well it accounts for our results, the predictions of adaptation-level theory will be fit below to the results of Experiments 2 and 4.

\section{Comparison-Induced Distortion Theory}

Choplin and Hummel (2002) proposed a theory of attribute-value evaluation, comparison-induced distortion theory, in which language-expressible magnitude comparisons (e.g., "line $A$ is longer than line $B$ ") bias evaluations. Choplin and Hummel demonstrated that this theory could account for the traditional, two-dimensional $\mathrm{ADE}$, and it might also account for the one-dimensional ADE-like effects found in Experiments 1-4.

Comparison-induced distortion theory starts with the observation that comparisons suggest quantifiable differences between the compared values (Rusiecki, 1985). For example, the comparison "line $A$ is longer than line $B$ " might bring to mind a difference of a couple of centimeters, not half a millimeter or an entire meter. To demonstrate this principle, we asked eight separate groups of pretest participants to imagine and draw lines that were shorter or longer than the line lengths in Experiment 2 (e.g., longer than a presented 30-mm line; only lengths that could have served as the base of a comparison in Experiment 2 were used). Relatively few participants imagined and drew extremely small or extremely large differences. For example, of the participants who imagined and drew lines that were longer than the $30-\mathrm{mm}$ line, only 1 out of 51 imagined and drew a line that was $30.5 \mathrm{~mm}$ long. No participant imagined and drew a line that was a meter long. Rather, the lines participants drew were distributed around an intermediate standard difference; the median line was $60 \mathrm{~mm}$ - a difference of $30 \mathrm{~mm}(S D=29.6$; the distribution of responses was positively skewed). This finding demonstrates that the comparison "longer than a 30-mm line" suggested a quantitative difference of approximately $30 \mathrm{~mm}$ (exact formal operational definition given shortly). We call this quantitative (i.e., this approximately $30-\mathrm{mm}$ difference) the comparison-suggested difference, because it is the difference that is suggested by the comparison.

To operationally define comparison-suggested differences for the line length comparisons in Experiments 2 and 4 , we used the differences between the presented lines and median responses in the pretest. The results from this pretest indicated that comparison-suggested differences were larger when the base of the comparison - that is, the second item or predicate of the comparison-was large. To capture this increase in the size of the comparison-suggested difference, we modeled the comparison-suggested difference, $D$, as a power function of the length of the basis of the comparison:

$$
\begin{aligned}
D= & S_{\mathrm{L}}^{k} \text {, when } S_{\mathrm{L}} \text { was the base of the comparison } \\
& \text { (i.e., in less-than comparisons) or } \\
D= & S_{\mathrm{S}}^{k} \text {, when } S_{\mathrm{S}} \text { was the base of the comparison } \\
& \text { (i.e., in more-than comparisons), }
\end{aligned}
$$

where $S_{\mathrm{L}}$ and $S_{\mathrm{S}}$ are the comparison-unbiased values ( $S$ stands for stimulus - i.e., actual or perceived values) of the larger and smaller items, respectively; and $k$ is the power to which the base was raised. The value for $k$ that best fit the pretest results by a minimized sum of squared deviations criterion was 1.04. By this operational definition, the difference suggested by the comparison "longer than a $30-\mathrm{mm}$ line" is $34.6 \mathrm{~mm}$ (i.e., $30^{1.04}$, or slightly larger than the median response of a $30-\mathrm{mm}$ difference reported above).

The basic idea underlying comparison-induced distortion theory is that comparisons bias evaluations toward comparison-suggested values. For example, in the comparison "the 34-mm line is longer than the $30-\mathrm{mm}$ line," the 34-mm line would be biased toward $64.6 \mathrm{~mm}$ (i.e., a comparison-suggested difference, $34.6 \mathrm{~mm}$, longer than the $30-\mathrm{mm}$ line). Likewise, the $30-\mathrm{mm}$ line would be biased toward $-0.6 \mathrm{~mm}$ (i.e., a comparison-suggested difference shorter than the 34-mm line; note that represented or evaluated values will not be negative, as we will discuss shortly). Formally, the comparison-suggested values of the smaller item (i.e., the value toward which the smaller item will be biased, $E_{\mathrm{S}}$; $E$ stands for expected) and the larger item $\left(E_{\mathrm{L}}\right)$ can be calculated from the comparisonsuggested difference, $D$ :

$$
E_{\mathrm{S}}=S_{\mathrm{L}}-D,
$$

and

$$
E_{\mathrm{L}}=S_{\mathrm{S}}+D
$$

With parameter $k$ in Equations $2 \mathrm{~A}$ and $2 \mathrm{~B}$ set at 1.04, the comparison-suggested value of a small item $\left(E_{\mathrm{S}}\right)$ will be 
approximately zero, and the comparison-suggested value of a large item $\left(E_{\mathrm{L}}\right)$ will be approximately twice the size of the base.

Represented values or evaluations are assumed to be a weighted mean of comparison-suggested and comparisonunbiased values:

$$
R_{\mathrm{S}}=w E_{\mathrm{S}}+(1-w) S_{\mathrm{S}},
$$

and

$$
R_{\mathrm{L}}=w E_{\mathrm{L}}+(1-w) S_{\mathrm{L}},
$$

where $w$ represents the proportional weight of the comparison-suggested values, is bound between 0 and 1 , and is low enough to prevent impossible values (e.g., negative line lengths) from being represented. With $w$ set at 0.1 , the comparison "the $34-\mathrm{mm}$ line is longer than the 30 -mm line" will bias the representation or evaluation of the $34-\mathrm{mm}$ line to be $37.1 \mathrm{~mm}$ and the representation or evaluation of the $30-\mathrm{mm}$ line to be $26.9 \mathrm{~mm}$. That is, the $34-\mathrm{mm}$ and $30-\mathrm{mm}$ lines will be evaluated or treated as if they were $37.1 \mathrm{~mm}$ and $26.9 \mathrm{~mm}$ long, respectively.

Whether or not comparison-induced distortion theory can account for the observed one-dimensional ADE-like decoy effects depends on which lines are compared and the sequences in which they are compared. In general, however, quantitative modeling reveals that comparisoninduced biases will almost always produce ADE-like decoy effects like those found in Experiments 1-4, as long as the decoy and the decoy-sided choice item are compared and most comparisons are between adjacent magnitude values (i.e., decoy and decoy-sided choice item, decoy-sided choice item and target, target and decoy-opposite choice item). Comparisons between nonadjacent items (e.g., decoy and decoy-opposite choice item) could create different patterns of biases from those observed in Experiments 1-4. This finding leaves two viable models of attribute-value evaluation that can account for the ADE-like decoy effects found in Experiments 1-4: adaptation-level theory and comparison-induced distortion theory.

\section{MODEL FITS}

We pitted Helson's (1964) adaptation-level theory and Choplin and Hummel's (2002) comparison-induced distortion theory against each other by fitting their predictions to the observed results. The quantitative predictions of adaptation-level theory (formalized in Equation 1) and of comparison-induced distortion theory (formalized in Equations 2A through 4B) were fit to the results of Experiments 2 and 4 .

The exact response proportions predicted by comparison-induced distortion theory depend on the comparisons participants make and the sequences in which they make them. The sequence in which participants compare values rarely has a dramatic effect on the results, but it does impact response proportions to some extent, because an item that has been compared once and then is compared again will have been biased by the first comparison. The comparison-biased represented value $(R$ after the first comparison; see Equations 4A and 4B) will then serve as the stimulus value ( $S$ for subsequent comparisons; see Equations 3A and 3B). To predict exact comparison-biased response proportions, constraints are needed on the set of comparisons participants make and on the sequences in which they make them.

To formalize the comparisons the participants might have made in Experiments 2 and 4, we consider the task constraints placed on participants in those studies (note, however, that other formalizations are possible and lead to similar results). The participants needed to eliminate the decoy as a viable response, and they could have done so on transitive grounds without measuring the quantitative difference between the decoy and the target. Two comparisons would be necessary to eliminate the decoy as a viable response on transitive grounds (i.e., a comparison between the decoy and the decoy-sided choice item and a comparison between the decoy-sided choice item and the target). Noting that the decoy-sided choice item was smaller than the target and that the decoy was smaller than the decoy-sided choice item, for instance, would have allowed participants to reject the decoy as a viable response without measuring the quantitative difference between the decoy and the target. The two comparisons required for this inference could be made in any of eight possible sequences; that is, there are 2 orders in which to make these comparisons (either the comparison between the decoy and the decoy-sided choice item or the comparison between the decoy-sided choice item and the target could be first) $\times 4$ ways in which the comparisons could be worded, because either item within each comparison could be the base of the comparison. Participants also needed to compare the choice items $(\mathrm{C}-$ and $\mathrm{C}+$ ) to the target. The comparisons required for the transitive inference necessarily include a comparison between the decoy-sided choice item and the target. In addition, the decoy-opposite choice item would have to be compared with the target. There are two possible ways in which participants could have compared the decoy-opposite choice item and the target - that is, either the choice item or the target could have been the base of comparison. Furthermore, participants could have either made the transitive inference first or compared the decoy-opposite item first. All combinations of these possibilities create 32 possible comparison sequences - that is, 8 (possible comparison sequences for the transitive inference) $\times 2$ (possible ways to compare the decoy-opposite item and the target) $\times 2$ (possible sequences in which participants could have executed these comparisons - either the transitive inference or the comparison of the decoy-opposite item and the target could have been first). The predictions of comparison-induced distortion theory were modeled using these 32 comparison sequences.

Adaptation-level theory (Equation 1) and comparisoninduced distortion theory (Equations 2A through 4B) 
predict that decoys will bias evaluations of line lengths in Experiments 2 and 4. Adaptation-level theory assumes that line lengths are evaluated by their distance from the adaptation level. In particular, $\mathrm{C}-$ and $\mathrm{C}+$ are evaluated by their distance from the adaptation level of the context of $\{\mathrm{C}-, \mathrm{C}+$, and the decoy $\}$, while the target is evaluated by its distance from the adaptation level of its own context $\{\mathrm{T}\}$. Judged similarity will be a function (described momentarily) of the differences in the evaluations of each of $\mathrm{C}-$ and $\mathrm{C}+$ from the evaluation of T (i.e., $d_{\mathrm{C}-\mathrm{T}}=\mid\left[S_{\mathrm{C}-}-\mathrm{AL}_{\{\mathrm{C}-, \mathrm{C}+\text {, decoy }\}}\right]-\left[S_{\mathrm{T}}-\right.$ $\left.\mathrm{AL}_{\{\mathrm{T}\}}\right]\left|; d_{\mathrm{C}+\mathrm{T}}=\right|\left[S_{\mathrm{C}+}-\mathrm{AL}_{\{\mathrm{C}-, \mathrm{C}+\text {, decoy }\}}\right]-\left[S_{\mathrm{T}}-\right.$ $\left.\mathrm{AL}_{\{\mathrm{T}\}}\right] \mid$; note that because subjective differences in line length tend to increase at approximately the same rate as objective differences [see Stevens, 1962], subjective differences were not scaled into these simulations). Since the adaptation level of the context that includes only $\mathrm{T}$ will be at T's value, these differences can simply be calculated from the distance between each of $\mathrm{C}-$ and $\mathrm{C}+$ and the adaptation level of the context $\{\mathrm{C}-, \mathrm{C}+$, and the decoy $\}$ (i.e., $d_{\mathrm{C}-\mathrm{T}}=\mid S_{\mathrm{C}-}-\mathrm{AL}_{\{\mathrm{C}-}, \mathrm{C}+$, decoy $\} \mid$; $\left.d_{\mathrm{C}+\mathrm{T}}=\left|S_{\mathrm{C}+}-\mathrm{AL}_{\{\mathrm{C}-, \mathrm{C}+, \text { decoy }\}}\right|\right)$. In comparisoninduced distortion theory, judged similarity will be a function of the distances between the comparisondistorted values of each choice item and the comparisondistorted value of the target (i.e., $d_{\mathrm{C}-\mathrm{T}}=R_{\mathrm{T}}-R_{\mathrm{C}-}$; $d_{\mathrm{C}+\mathrm{T}}=R_{\mathrm{C}+}-R_{\mathrm{T}}$ ). For both theories, these scores were converted to similarity scores $(\eta)$ using an exponential decay function:

$$
\eta_{\mathrm{C}-\mathrm{T}}=e^{-c d_{\mathrm{C}-\mathrm{T}}}
$$

and

$$
\eta_{\mathrm{C}+\mathrm{T}}=e^{-c d_{\mathrm{C}+\mathrm{T}}},
$$

where $c$ is a free parameter used to scale similarities (Shepard, 1987). Predicted choice frequencies were calculated from these similarity scores using the choice axiom:

$$
\begin{aligned}
p\left(\eta_{\mathrm{C}-\mathrm{T}}>\eta_{\mathrm{C}+\mathrm{T}}\right) & =\frac{\eta_{\mathrm{C}-\mathrm{T}}}{\left(\eta_{\mathrm{C}-\mathrm{T}}+\eta_{\mathrm{C}+\mathrm{T}}\right)}, \\
\operatorname{count}\left(\eta_{\mathrm{C}-\mathrm{T}}>\eta_{\mathrm{C}+\mathrm{T}}\right) & =N * p\left(\eta_{\mathrm{C}-\mathrm{T}}>\eta_{\mathrm{C}+\mathrm{T}}\right) ; \\
p\left(\eta_{\mathrm{C}+\mathrm{T}}>\eta_{\mathrm{C}-\mathrm{T}}\right) & =\frac{\eta_{\mathrm{C}+\mathrm{T}}}{\left(\eta_{\mathrm{C}+\mathrm{T}}+\eta_{\mathrm{C}-\mathrm{T}}\right)}, \\
\operatorname{count}\left(\eta_{\mathrm{C}+\mathrm{T}}>\eta_{\mathrm{C}-\mathrm{T}}\right) & =N * p\left(\eta_{\mathrm{C}+\mathrm{T}}>\eta_{\mathrm{C}-\mathrm{T}}\right),
\end{aligned}
$$

where $N$ is the number of responses collected in each decoy condition (excluding decoy responses).

A minimized negative log-likelihood criterion was used to find the best fit for the free parameters of the models. Adaptation-level theory had one free parameter, $c$, the value used to scale similarities in Equations 5A and 5B. Comparison-induced distortion theory had three values that were not known a priori: $k$ in Equations 2A and $2 \mathrm{~B}, w$ in Equations $4 \mathrm{~A}$ and $4 \mathrm{~B}$, and $c$ in Equations $5 \mathrm{~A}$ and $5 \mathrm{~B}$. On the basis of the pretest described above, parameter $k$ was set to 1.04 , so it was not a free param- eter. Comparison-induced distortion theory, therefore, had two free parameters, $w$ and $c$. Each model was fit to the results of the six decoy conditions (conditions Dand $\mathrm{D}+$ in Experiment 2 and conditions $\mathrm{D}---, \mathrm{D}--$, $\mathrm{D}++$, and $\mathrm{D}+++$ in Experiment 4) simultaneously.

The results of these fits are presented in Table 1. For adaptation-level theory, the best-fitting value for parameter $c$ by the minimized negative log-likelihood criterion was 0.03 . Minimized negative log-likelihood was 13.55 . For comparison-induced distortion theory, the best-fitting value for parameter $c$ was 28.82, and the best-fitting value for $w$ was .001 . Minimized negative log-likelihood was 8.92 . The finding that minimized negative log-likelihood was smaller for comparison-induced distortion theory than for adaptation-level theory indicates that comparisoninduced distortion theory fits the data better than does adaptation-level theory. Comparison-induced distortion theory's better fit cannot be attributed to the fact that it had more free parameters than did adaptation-level theory, as indicated by scores on the Bayesian information criterion. Comparison-induced distortion theory's score on this criterion was 19.40, whereas adaptation-level theory's score was 27.88 (smaller values indicate a better fit). These results suggest that comparison-induced distortion theory provides a better account of the one-dimensional decoy effects observed in Experiments 2 and 4 than does adaptation-level theory. Furthermore, comparison-induced distortion theory can account for the changes in attributevalue evaluation found in the traditional, two-dimensional ADE (Choplin \& Hummel, 2002), and adaptation-level theory cannot.

\section{GENERAL DISCUSSION}

Extant theories of decoy effects on attribute-value evaluation were assessed with respect to their ability to account for the one-dimensional analogue of the ADE demonstrated in Experiments 1-4. In these four experiments, participants judged the similarity of two stimuli $(\mathrm{C}-$ and $\mathrm{C}+)$ to a third stimulus $(\mathrm{T})$. These three stimuli were designed so that $\mathrm{C}-$ had a smaller value than $\mathrm{T}$, $\mathrm{C}+$ had a larger value than $\mathrm{T}$, and the difference between $\mathrm{C}-$ and $\mathrm{T}$ was approximately the same as the difference between $\mathrm{C}+$ and $\mathrm{T}$. A decoy was also introduced into the set of items being evaluated. In Experiments 1-3, participants viewed a decoy whose magnitude value was either just smaller than $\mathrm{C}-(\mathrm{D}-)$ or just larger than $\mathrm{C}+$ $(\mathrm{D}+)$. Participants who viewed $\mathrm{D}-$ as the decoy tended to judge $\mathrm{C}-$ to be more similar to $\mathrm{T}$ than they did $\mathrm{C}+$. By contrast, participants who viewed $\mathrm{D}+$ as the decoy tended to judge $\mathrm{C}+$ to be more similar to $\mathrm{T}$ than they did $\mathrm{C}-$. Experiment 1 demonstrated this decoy effect with ovals that varied in aspect ratio using a forced choice paradigm. Experiment 2 demonstrated the effect with line segments using a forced choice paradigm. Experiment 3 demonstrated this effect for line segments using a similarity rating paradigm. Experiment 4 was analo- 
gous to Experiment 2 and investigated the effects of decoys that were smaller than $\mathrm{D}-(\mathrm{D}--, \mathrm{D}---)$ or larger than $\mathrm{D}+(\mathrm{D}++, \mathrm{D}+++)$.

Parducci's $(1965,1995)$ range-frequency theory, Krumhansl's (1978) distance-density model, Tversky's (1977) diagnosticity principle, and reference point theories (e.g., Holyoak \& Mah, 1982) were unable to account for the qualitative results of Experiments 1-4. Helson's (1964) adaptation-level theory (under the assumption that the target was placed in a separate context from the choice items and the decoy) and comparison-induced distortion theory (Choplin \& Hummel, 2002) were both able to account for the qualitative results. Quantitative fits to the results of Experiments 2 and 4 revealed that comparison-induced distortion theory provides a better account of one-dimensional ADE-like decoy effects than does adaptation-level theory.

The findings reported here, along with those reported by Choplin and Hummel (2002), suggest that comparisonaltered attribute evaluations play a role in the ADE. This result does not mean, of course, that comparison-induced distortions are the only factor responsible for the ADE. Other factors could affect attribute-value evaluations, and factors other than attribute-value evaluations likely play a role in the ADE (see Wedell \& Pettibone, 1996). Furthermore, comparison-induced distortion theory cannot explain all decoy effects (e.g., phantom decoy effects; see Highhouse, 1996; Pettibone \& Wedell, 2000). Nevertheless, comparison-induced distortions are an important factor mediating some decoy effects on choice.

\section{REFERENCES}

Ariely, D., \& Wallsten, T. S. (1995). Seeking subjective dominance in multidimensional space: An explanation of the asymmetric dominance effect. Organizational Behavior \& Human Decision Processes, 63, 223-232.

CHOPLIN, J. M., \& Hummel, J. E. (2002). Magnitude comparisons distort mental representations of magnitude. Journal of Experimental Psychology: General, 131, 270-286.

Doyle, J. R., O'Connor, D. J., Reynolds, G. M., \& Bottomley, P. A. (1999). The robustness of the asymmetrically dominated effect: Buying frames, phantom alternatives, and in-store purchases. Psychology \& Marketing, 16, 225-243.

Frederick, S., \& Loewenstein, G. (1999). Hedonic adaptation. In D. Kahneman, E. Diener, \& N. Schwarz (Eds.), Well-being: The foundations of hedonic psychology (pp. 302-329). New York: Sage.

GARNER, W. R. (1974). The processing of information and structure. Hillsdale, NJ: Erlbaum.

Helson, H. (1964). Adaptation level theory: An experimental and systematic approach to behavior. New York: Harper.

Highrouse, S. (1996). Context-dependent selection: The effects of decoy and phantom job candidates. Organizational Behavior \& Human Decision Processes, 65, 68-76.

HOLYOAK, K. J., \& MAH, W. A. (1982). Cognitive reference points in judgments of symbolic magnitude. Cognitive Psychology, 14, 328-352.
Huber, J., Payne, J. W., \& Puto, C. (1982). Adding asymmetrically dominated alternatives: Violations of regularity and the similarity hypothesis. Journal of Consumer Research, 9, 90-98.

Huber, J., \& Puto, C. (1983). Market boundaries and product choice: Illustrating attraction and substitution effects. Journal of Consumer Research, 10, 31-44.

KrumhansL, C. L. (1978). Concerning the applicability of geometric models to similarity data: The interrelationship between similarity and spatial density. Psychological Review, 85, 445-463.

Medin, D. L., Goldstone, R. L., \& MARKMAN, A. B. (1995). Comparison and choice: Relations between similarity processes and decision processes. Psychonomic Bulletin \& Review, 2, 1-19.

PAN, Y., O'CURRY, S., \& PITTS, R. (1995). The attraction effect and political choice in two elections. Journal of Consumer Psychology, 4, 85-101.

PARducCI, A. (1965). Category judgments: A range-frequency model. Psychological Review, 72, 407-418.

PARDUCCI, A. (1995). Happiness, pleasure, and judgment: The contextual theory and its applications. Mahwah, NJ: Erlbaum.

Pettibone, J. C., \& Wedell, D. H. (2000). Examining models of nondominated decoy effects across judgment and choice. Organizational Behavior \& Human Decision Processes, 81, 300-328.

RoE, R. M., Busemeyer, J. R., \& TownSEND, J. T. (2001). Multialternative decision field theory: A dynamic connectionist model of decision making. Psychological Review, 108, 370-392.

RUSIECKI, J. (1985). Adjectives and comparison in English. New York: Longman.

Sedikides, C., Ariely, D., \& Olsen, N. (1999). Contextual and procedural determinants of partner selection: Of asymmetric dominance and prominence. Social Cognition, 17, 118-139.

ShEPARD, R. N. (1987). Toward a universal law of generalization for psychological science. Science, 237, 1317-1323.

Simonson, I. (1989). Choice based on reasons: The case of attraction and compromise effects. Journal of Consumer Research, 16, 158-174.

Simonson, I., \& Tversky, A. (1992). Choice in context: Tradeoff contrast and extremeness aversion. Journal of Marketing Research, 29, 281-295.

STEVENS, S. S. (1962). The surprising simplicity of sensory metrics. American Psychologist, 17, 29-39.

TVersky, A. (1977). Features of similarity. Psychological Review, $\mathbf{8 4}$, 327-352.

TVERSKY, A., \& KAHNEMAN, D. (1991). Loss aversion in riskless choice: A reference-dependent model. Quarterly Journal of Economics, 106, 1039-1061.

TVERSKY, A., \& SIMONSON, I. (1993). Context-dependent preferences. Management Science, 39, 1179-1189.

VolkmanN, J. (1951). Scales of judgment and their implications for social psychology. In J. H. Rohrer \& M. Sherif (Eds.), Social psychology at the crossroads (pp. 273-296). New York: Harper.

WeDELL, D. H. (1991). Distinguishing among models of contextually induced preference reversals. Journal of Experimental Psychology: Learning, Memory, \& Cognition, 17, 767-778.

WEDELL, D. H. (1995). Contrast effects in paired comparisons: Evidence for both stimulus-based and response-based processes. Journal of Experimental Psychology: Human Perception \& Performance, 21, 1158-1173.

Wedell, D. H., \& Pettibone, J. C. (1996). Using judgments to understand decoy effects in choice. Organizational Behavior \& Human Decision Processes, 67, 326-344.

(Manuscript received April 7, 2003; revision accepted for publication May 13, 2004.) 